\title{
Sistemas silvipastoril e tradicional na Amazônia Oriental - produção e qualidade da carcaça e carne de búfalos
}

\section{Traditional and silvipastoral system on Eastern Amazon - production and carcass and meat quality from buffalo}

\author{
Maria Regina Sarkis Peixoto Joele ${ }^{1 *}$; José de Brito Lourenço Junior²; \\ Cristian Faturi ${ }^{3}$; Alexandre Rossetto Garcia ${ }^{4}$; Benjamim Souza Nahúm; \\ Lúcia Fátima Henriques Lourenço ${ }^{2}$; Kelly Connor Cavalcante Oliveira ${ }^{6}$
}

\section{Resumo}

Objetivou-se avaliar comparativamente as características físicas e físico-químicas das carcaças de búfalos (Bubalus bubalis), Murrah/Mediterrâneo, terminados em Sistema Tradicional, com pastagem cultivada e suplementação mineral, com animais terminados em Sistema Silvipastoril, com suplementação mineral e ração composta por resíduos agroindustriais, em Unidades de Pesquisa da Embrapa Amazônia Oriental, em Belém, Pará. Os abates ocorreram em abatedouro comercial, com posteriores avaliações quantitativas e qualitativas das carcaças. $\mathrm{O}$ delineamento experimental foi inteiramente casualizado, submetidos à análise de variância e médias comparadas pelo teste ' $\mathrm{t}$ ', a $5 \%$ de significância. Os animais do Sistema Silvipastoril, abatidos com pesos similares aos do Sistema Tradicional, apresentaram melhor conformação de carcaça e acabamento de gordura, com diferenças significativas $(\mathrm{P}<0,05)$ no marmoreio do músculo Longissimus dorsi e nos pesos de quartos traseiros, com aumento na produção de carnes nobres. Embora as carcaças tenham apresentado $\mathrm{pH}$ final no limite de carne DFD (dark, firm e dry), as análises de cor e textura objetivas permitem considerá-la com qualidade normal.

Palavras-chave: Sistemas agroflorestais, produção de carne, subprodutos da agroindústria

\footnotetext{
Abstract

The objective was to comparatively evaluate the physical and physico-chemical properties of buffaloes carcasses (Bubalus bubalis), Murrah/Mediterranean finished in Traditional System, with pasture and mineral supplements, with buffalo, from same race, finished in a Silvopastoral System, with mineral supplementation and diet composed of organic residues, in research unit of Embrapa Eastern Amazon, Belém, Para State, Brazil. The slaughter occurred in commercial slaughterhouse, following its normal flow, with quantitative and qualitative evaluations of the carcasses. The experimental design was randomized, with the data submitted to ANOVA and means compared using the ' $t$ ' test at $5 \%$ significance. Animals from Silvopastoral System slaughtered at weights similar to those of Traditional System in different ages, showed better carcass conformation and fat distribution, with significant differences $(\mathrm{P}<0.05)$ in marbling in the Longissimus dorsi muscle and weight of the hindquarters, with increased

${ }^{1}$ Prof. do Instituto Federal de Educação, Ciência e Tecnologia do Pará, Campus Castanhal, Castanhal, PA. E-mail: reginajoele@ hotmail.com

${ }^{2}$ Profs. da Universidade Federal do Pará, UFPA, Belém, PA. E-mail: joselourencojr@yahoo.com.br; luciahl@ufpa.br

${ }^{3}$ Prof. da Universidade Federal Rural da Amazônia, UFRA, Belém, PA. E-mail: cfaturi@ufra.edu.br

${ }^{4}$ Pesquisador, Embrapa Pecuária Sudeste, São Carlos, SP. E-mail: agarcia@cppse.embrapa.br

${ }^{5}$ Pesquisador, Embrapa Amazônia Oriental, Belém, PA. E-mail: nahum@cpatu.embrapa.br

${ }^{6}$ Discente de Doutorado, UFPA, Belém, PA. E-mail: kellyconor@hotmail.com

* Autor para correspondência
} 
production of prime meat. Although the carcasses have submitted final $\mathrm{pH}$ within the limits of DFD meat (dark, firm and dry), the analysis of color and texture of meat allow us to consider normal quality.

Key words: Agroforestry systems, meat production system, animal products, agroindustry by-products

\section{Introdução}

A bubalinocultura de corte é atividade que tem conquistado cada vez mais espaço na pecuária brasileira, principalmente, em função da boa adaptabilidade desses animais aos trópicos. Contudo, para que a carne bubalina conquiste a mesa dos consumidores, os animais devem ser jovens, com carcaça de melhor acabamento, em termos de distribuição de gordura de cobertura e espessura de gordura traseira, com melhores escores de marmoreio e carne mais macia (JORGE et al., 2006).

Em sistemas tradicionais de criação na Amazônia, sem uso de inovações tecnológicas, a baixa rentabilidade da bubalinocultura torna essa atividade pouco atrativa economicamente, com o prognóstico de que em médio e longo prazo, somente permanecerão nela os produtores competentes para se adaptarem à nova realidade das mudanças econômicas. (LOURENÇO JÚNIOR; GARCIA, 2006).

Nas regiões tropicais, devido às condições climáticas e manejo inadequado do animal e da pastagem, há necessidade de práticas que contribuam para o bem-estar animal, dentre elas as que envolvam disponibilidade de água e sombreamento, basicamente, para os búfalos. No verão, as elevadas temperaturas, umidade relativa do ar e calor podem causar desconforto e até morte de animais menos adaptados, com redução da ingestão alimentar e aumento da energia disponibilizada, para manutenção da homeotermia, o que diminui a eficiência reprodutiva e a produtividade, em carne e leite (BERNARDES, 2007).

Os Sistemas Silvipastoris são caracterizados pela combinação intencional de árvores, pastagem e animais, na mesma área e ao mesmo tempo. Os componentes apresentam manejo de forma integrada, com objetivo de incrementar a produtividade por unidade de área, com interações em todos os sentidos e em diferentes magnitudes (CASTRO et al., 2008; MORAES JUNIOR et al., 2010).

O conhecimento das características quantitativas e qualitativas de carcaças é fundamental para a indústria da carne, que busca a melhoria da qualidade potencial do produto final (SILVA et al., 2006). De modo genérico, pode-se dizer que as variações encontradas na composição de carcaça são devidas ao manejo alimentar, confinamento ou criação extensiva, sexo, idade do animal, grupo genético, e as interações entre esses fatores.

$\mathrm{Na}$ determinação de rendimentos de abate e carcaça de animais confinados, bovinos e búfalos Mediterrâneo, Rodrigues et al. (2003) concluíram que estes apresentam menor rendimento de carcaça, devido à maior proporção de cabeça, patas, couro e vísceras, com maior proporção do corte traseiro. Rao et al. (2009), ao avaliarem o rendimento e características de carcaça de búfalos, no sul da Índia, observaram maiores rendimentos de carcaça, relação carne:ossos e área de olho de lombo no grupo com idade intermediária (24 a 48 meses).

Assim, este trabalho teve como objetivo avaliar os efeitos do Sistema Silvipastoril, com suplementação alimentar de resíduos agroindustriais e do Sistema Tradicional, sobre as características físicas e fisicoquímicas das carcaças de búfalos (Bubalus bubalis), criados na Amazônia Oriental.

\section{Material e Métodos}

O experimento foi realizado nas Unidades de Pesquisa Animal "Senador Álvaro Adolpho" (1 ${ }^{\circ} 25^{\prime} \mathrm{S}$ e 48 $\left.26^{\prime} \mathrm{W}\right)$, com Sistema Silvipastoril, e "Dr. Felisberto Camargo" (01²5'S e 48²6’W), com Sistema Tradicional, pertencentes à Embrapa Amazônia Oriental, Belém, Pará. 
O Sistema Silvipastoril foi implantado em área experimental de 5,4 ha, dividida em cinco piquetes, com gramínea mombaça (Panicum maximum cv. Mombaça), manejada em sistema rotacionado, em ciclos de 30 dias, com cercas perimetrais e divisórias eletrificadas, com dois fios de arame liso, onde estão plantados mogno africano (Khaya ivorensis) e nim indiano (Azadirachta indica), e redondel central, com bebedouro e cocho cobertos, para suplementação mineral. Durante o período experimental, os animais tiveram acesso a sal mineral ad libitium e ração preparada com resíduos agroindustriais, uma vez ao dia, na quantidade de $1 \%$ do peso vivo.

No Sistema Tradicional, os animais foram alimentados, exclusivamente, com pastagem de quicuio-da-amazônia (Brachiaria humidicola), em dois piquetes, com cercas perimetrais e divisórias eletrificadas, acesso a água para bebida e sal mineral, ad libitum.

Foram utilizados 22 machos bubalinos, mestiços Murrah/Mediterrâneo, dos quais sete foram criados, recriados e terminados em Sistema Tradicional, com ganho de peso médio diário de $0,3 \mathrm{~kg} /$ animal e taxa de ocupação $1 \mathrm{UA} / \mathrm{ha}$, e quinze animais foram transportados para o Sistema Silvipastoril, distante $5 \mathrm{~km}$, para terminação, com suplementação alimentar de rações elaboradas com resíduos agroindustriais, com ganho de peso de 1 $\mathrm{kg} /$ animal/dia, em taxa de ocupação média de 3,75 UA. Foram seguidas prerrogativas sanitárias, no tocante a vacinações, exames periódicos e controle de parasitoses.

Foram selecionados, aleatoriamente, entre os tratamentos, onze animais do Sistema Silvipastoril e sete do Sistema Tradicional, pesados após 14 horas de jejum, antes do embarque, em balança comercial tipo curral (Peso do animal vivo PV). Em seguida, transportados ao abatedourofrigorífico, em percurso de 30 minutos. O abate ocorreu de acordo com as normas do RIISPOA (BRASIL, 1997). Após separação, as carcaças foram pesadas, na sala de abate, para obtenção do peso de carcaça quente (PCQ), em balança digital da marca Tendal, e resfriadas por 24 horas, em câmara fria, à temperatura de $2-4{ }^{\circ} \mathrm{C}$. Posteriormente, foram retiradas e novamente pesadas, para determinação do peso de carcaça fria (PCF).

A meia-carcaça esquerda foi separada nos cortes: serrote, que envolve a região posterior da carcaça, separada do dianteiro, entre a quinta e sexta costelas; dianteiro, que compreende pescoço, paleta, braço e cinco costelas; e o costilhar, que abrange as costelas, a partir da sexta, mais os músculos abdominais. Após a separação dos cortes fez-se a pesagem, para calcular a percentagem em relação à meia-carcaça, e foram realizadas medições de temperatura corporal, $\mathrm{pH}$ e comprimento de braço e perna, espessura de coxão e perímetro de braço.

$\mathrm{Na}$ meia-carcaça direita foi feito um corte entre a $12^{\mathrm{a}}$ e a $13^{\mathrm{a}}$ costelas, com o objetivo de expor o músculo Longissimus dorsi, para a mensuração da área de olho de lombo(AOL), com contorno em papel vegetal. Ao redor da AOL foi medida a espessura de gordura de cobertura (EGC), com paquímetro de aço inoxidável, e marmoreio, avaliado em escala de 18 pontos, segundo Müller (1987). Com esses dados foram estimados os parâmetros de composição de carcaça, através das equações descritas por Felício, Picchi e Corte (1979).

Foram retiradas amostras do músculo Longissimus dorsi, entre a $10^{\mathrm{a}}$ e $12^{\mathrm{a}}$ costelas, separadas em bifes de $2,5 \mathrm{~cm}$, e embaladas, à vácuo, e resfriadas por 48 horas, para avaliar a cor instrumental, em aparelho Minolta CR 400, após exposição ao oxigênio por 30 minutos, utilizandose iluminante D65, e textura objetiva (força de cisalhamento das fibras musculares), em aparelho Brookfield QTS 25 e célula "Warner-Bratzler Shear" (WHEELER; KOOHMARAIE; SHACKELFORD, 1995), com média de seis leituras por bife.

$\mathrm{O}$ delineamento experimental foi inteiramente casualizado, com dois tratamentos (sistemas de produção) e os dados coletados foram submetidos 
à análise de variância, através do comando PROC GLM, em pacote estatístico SAS.

\section{Resultados e Discussão}

Não foram detectadas diferenças significativas nas características quantitativas das carcaças (Tabela 1), o que pode ser atribuído, segundo Jorge et al. (2005) ao peso de abate semelhante dos animais, considerando-se que esses parâmetros são altamente relacionados, quando o rendimento de carcaça não é afetado.

Tabela 1. Médias, desvio padrão e coeficiente de variação das características quantitativas da carcaça dos búfalos criados em Sistema Silvipastoril (SSP) e Sistema Tradicional (ST)

\begin{tabular}{|c|c|c|c|}
\hline \multirow{2}{*}{ Variável } & \multicolumn{2}{|c|}{ Sistema de criação } & \multirow{2}{*}{$\mathrm{CV}(\%)$} \\
\hline & SSP & ST & \\
\hline Peso vivo, $\mathrm{kg}$ & $650,3^{\mathrm{a}} \pm 46,5$ & $665,3^{\mathrm{a}} \pm 51,1$ & 8,36 \\
\hline Peso carcaça quente, $\mathrm{kg}$ & $318,9^{\mathrm{a}} \pm 38,5$ & $309,6^{\mathrm{a}} \pm 36,7$ & 13,30 \\
\hline Rendimento de carcaça, $\%$ & $49,53^{\mathrm{a}} \pm 3,0$ & $46,87^{b} \pm 4,0$ & 8,45 \\
\hline Peso carcaça fria, $\mathrm{kg}$ & $310,01^{\mathrm{a}} \pm 37,4$ & $299,5^{\mathrm{a}} \pm 36,9$ & 11,86 \\
\hline Comprimento de carcaça, cm & $153,3^{b} \pm 7,2$ & $160,4^{\mathrm{a}} \pm 1,7$ & 3,75 \\
\hline Comprimento de perna, $\mathrm{cm}$ & $86,4^{\mathrm{a}} \pm 2,2$ & $88,0^{\mathrm{a}} \pm 2,7$ & 2,74 \\
\hline Comprimento de braço, $\mathrm{cm}$ & $44,5^{\mathrm{a}} \pm 1,5$ & $45,1^{\mathrm{a}} \pm 1,2$ & 3,04 \\
\hline Peso dianteiro, $\mathrm{kg}$ & $128,5^{\mathrm{a}} \pm 23,7$ & $129,3^{\mathrm{a}} \pm 14,4$ & 13,22 \\
\hline Percentagem dianteiro, $\%$ & $41,45^{\mathrm{b}} \pm 3,0$ & $43,17^{\mathrm{a}} \pm 2,3$ & 6,94 \\
\hline Peso costilhar, kg & $35,0^{\mathrm{a}} \pm 4,1$ & $31,8^{\mathrm{a}} \pm 5,8$ & 15,36 \\
\hline Costilhar, \% & $11,28 \mathrm{a} \pm 1,1$ & $10,44^{\mathrm{a}} \pm 0,9$ & 9,15 \\
\hline Peso traseiro, $\mathrm{kg}$ & $164,4^{\mathrm{a}} \pm 14,8$ & $146,6^{b} \pm 19,4$ & 11,28 \\
\hline Traseiro, $\%$ & $53,03^{\mathrm{a}} \pm 1,0$ & $48,94^{b} \pm 2,1$ & 5,79 \\
\hline Carne, $\%$ & $68,72^{\mathrm{a}} \pm 1,75$ & $69,19^{\mathrm{a}} \pm 2,1$ & 2,65 \\
\hline Gordura, \% & $14,92^{\mathrm{a}} \pm 1,34$ & $13,13^{\mathrm{a}} \pm 1,5$ & 9,49 \\
\hline Ossos, $\%$ & $16,36^{\mathrm{a}} \pm 2,3$ & $17,68^{\mathrm{a}} \pm 3,4$ & 9,25 \\
\hline Relação porção comestível/ossos & $5,15^{\mathrm{a}} \pm 0,5$ & $4,71^{\mathrm{a}} \pm 0,5$ & 11,42 \\
\hline
\end{tabular}

${ }^{\text {ab }}$ Médias seguidas de letras diferentes, na mesma linha, apresentam diferenças significativas entre si $(\mathrm{P}<0,05)$.

Fonte: Elaboração dos autores.

Obteve-se bom rendimento de carcaça quente nos dois sistemas de criação (Sistema Silvipastoril e Sistema Tradicional), sendo que os animais do Sistema Silvipastoril apresentaram valores superiores $(\mathrm{P} \leq 0,05)$. De acordo com Macedo, Bianchini Sobrinho e Resende (2000), bubalinos não castrados, terminados em confinamento e em regime de pastagem, obtiveram rendimento de carcaça quente, respectivamente, de 50,81\% e 48,91\%. O rendimento de carcaça de búfalos é menor, devido à maior proporção de cabeça, patas, couro e vísceras, embora apresentem maior proporção do corte serrote, em função do peso da carcaça (RODRIGUES et al., 2003).

Os animais terminados em Sistema Silvipastoril apresentaram maior peso de carcaça quente, com menor comprimento de carcaça e maior percentual de traseiro especial $(\mathrm{P} \leq 0,05)$, quando comparados com os animais do Sistema Tradicional, onde estão localizados os cortes mais nobres da carcaça, o que indica que possuem melhor acabamento. Nesse sistema, os animais apresentaram percentual de traseiro semelhante aos encontrados por Vaz et al. (2003), em bubalinos Mediterrâneo, castrados e terminados em confinamento $(50,1 \%)$. O maior 
percentual de traseiro na carcaça é importante para o sistema produtivo, principalmente, para a cadeia frigorífica, devido aos seus cortes nobres e melhores preços de comercialização (MISSIO et al., 2010).

$\mathrm{Na}$ avaliação final da carcaça é importante verificar a sua composição, pois pesquisas indicam que o maior percentual de gordura na carcaça de animais mais jovens é resultado da alteração na composição do ganho, considerando-se que, durante a fase de crescimento do animal, a gordura é o tecido que apresenta o desenvolvimento mais tardio, mas é depositada em todas as idades, em função da velocidade de ganho de peso e peso corporal do animal. Os animais do Sistema Silvipastoril apresentaram maior percentual $(\mathrm{P} \geq 0,05)$ de gordura e menor $(P \geq 0,05)$ de carne, em comparação com os animais do Sistema Tradicional. Em trabalhos com animais da raça Mediterrâneo, Andrighetto et al. (2008) determinaram valores semelhantes de músculos, gordura e ossos, respectivamente, de 55,86; 27,64 e 16,51\%. Apesar das percentagens de carne e ossos e relação porção comestível/ossos não terem sofrido o efeito do sistema de terminação, pode-se considerar que os animais desta pesquisa apresentaram bom desenvolvimento de massa muscular, com acabamento de gordura na carcaça.

Entre as características qualitativas da carcaça e da carne dos bubalinos, de acordo com os sistemas de criação (Tabela 2), somente o marmoreio apresentou diferença significativa $(\mathrm{P} \leq 0,05)$. O limite de $\mathrm{pH}$ para classificar uma carne como Normal ou DFD (Dark, firm e dry), encontra-se entre 6,0 a 6,2 (ALVES; MANCIO, 2007). Portanto, os valores do presente trabalho, em torno de 6,0, estão no limite de carne DFD. Ao ser considerado o limite estabelecido pela União Européia, abaixo de 5,9, os valores encontrados neste trabalho seriam limitantes, o que pode ser explicado pela interferência dos fatores pré-abate ou abate, tais como transporte, excesso de jejum e/ou precária insensibilização no abatedouro frigorífico. Andrighetto et al. (2008) e Spanghero et al. (2004), encontraram valores de $\mathrm{pH}$ próximos de 5,5 no músculo Longissimus dorsi de bubalinos Murrah e Mediterrâneo, respectivamente.

Tabela 2. Médias e coeficientes de variação das características qualitativas das carcaças dos búfalos, criados em Sistema Silvipastoril (SSP) e Sistema Tradicional (ST)

\begin{tabular}{lccc}
\hline \multicolumn{1}{c}{ Variável } & \multicolumn{2}{c}{ Sistema } & CV \\
\hline & SSP & ST & $(\%)$ \\
pH inicial & $7,08^{\mathrm{a}} \pm 0,2$ & $7,00^{\mathrm{a}} \pm 0,2$ & 2,60 \\
pH final & $6,09^{\mathrm{a}} \pm 0,1$ & $5,97^{\mathrm{a}} \pm 0,2$ & 2,17 \\
Espessura de gordura, mm & $5,81^{\mathrm{a}} \pm 1,91$ & $4,52^{\mathrm{a}} \pm 1,11$ & 20,81 \\
Área de olho de lombo (AOL), cm & $71,16^{\mathrm{a}} \pm 8,6$ & $67,76^{\mathrm{a}} \pm 9,3$ & 12,72 \\
Marmoreio, pontos & $7,27^{\mathrm{a}} \pm 2,8$ & $3,14^{\mathrm{b}} \pm 0,62$ & 14,73 \\
Força de cisalhamento (kgf) & $3,84^{\mathrm{a}} \pm 0,4$ & $3,98^{\mathrm{a}} \pm 0,1$ & 9,64 \\
Cor & & & \\
$\mathrm{L}^{*}$ & & & 4,56 \\
$\mathrm{a}^{*}$ & $59,13^{\mathrm{a}} \pm 4,6$ & $58,90^{\mathrm{a}} \pm 4,8$ & 2,49 \\
$\mathrm{~b}^{*}$ & $26,60^{\mathrm{a}} \pm 2,5$ & $26,54^{\mathrm{a}} \pm 9,9$ & 2,89 \\
\hline
\end{tabular}

${ }^{\mathrm{ab}}$ Médias seguidas de letras diferentes, na mesma linha, apresentam diferença significativa entre si $(\mathrm{P}<0,05)$.

Fonte: Elaboração dos autores.

O marmoreio da carne representa a quantidade de gordura intramuscular e foi verificado, em maior grau, nos bubalinos do Sistema Silvipastoril
$(\mathrm{P} \leq 0,05)$. Embora considerado baixo, quando comparado às raças bovinas especializadas, essa classificação foi resultante do maior acúmulo de 
gordura devido à alimentação, o que promoveu alteração na composição do ganho de peso desses animais, que passaram a depositar mais gordura, fato confirmado pela correlação positiva entre características relacionadas à gordura, tanto na carcaça como na carne. A gordura de marmoreio se desenvolve quando o animal ganha peso, em elevadas taxas, ou quando avança em idade ou peso corporal, sendo a última a ser depositada e primeira a ser mobilizada, quando o animal sofre restrição alimentar (PACHECO et al., 2005).

De acordo com os resultados encontrados, a carne apresentou coloração vermelho intenso, o que pode ter sido influenciado pelo elevado $\mathrm{pH}$, sem diferenças significativas entre os animais dos dois sistemas de criação. A cor da carne é fator importante na comercialização, pois o consumidor rejeita produto de coloração mais escura, por associá-lo com animais mais velhos ou má conservação da carne (PACHECO et al., 2005).

$\mathrm{Na}$ presente pesquisa foram encontrados valores de força de cisalhamento inferiores a 5,0 kgf, considerado por Andrighetto et al. (2008) como limite máximo para se ter carne macia. Valor menor na carne dos animais do Sistema Silvipastoril devese, possivelmente, ao maior marmoreio. Restle et al. (2002), ao compararem animais abatidos aos 24 ou 14 meses de idade, observaram que, ao reduzir a idade de abate em um ano, a maciez da carne foi melhorada em $30 \%$, o que demonstra que carnes mais macias foram relacionadas com maior grau de marmoreio $(r=0,28)$ e carcaças com maior percentagem $(\mathrm{r}=0,27)$ e quantidade total $(\mathrm{r}$ $=0,31$ ) de gordura. A maciez da carne é o fator de maior variabilidade e atributo mais desejável pelo consumidor e pode ser estabelecida avaliandose a textura, de forma subjetiva, através de painel sensorial, ou objetiva, utilizando-se texturômetro, que determina a força de cisalhamento das fibras musculares superficiais da carne.

As correlações entre características das carcaças dos animais experimentais (Tabela 3) indicaram associação altamente positiva entre peso do animal vivo e pesos de carcaça quente $(\mathrm{r}=0,88)$ e fria $(r=0,88)$, pesos de quartos traseiros $(r=0,87)$, dianteiros $(\mathrm{r}=0,73)$ e costilhar $(\mathrm{r}=0,88)$, percentual de gordura $(r=0,80)$ e relação carne/ossos $(0,78)$.

Tabela 3. Correlações entre características avaliadas nos animais experimentais (Coeficientes de Pearson).

\begin{tabular}{llllllc}
\hline & PAV & PCQ & PCF & PQD & PQT & Gordura \\
\hline PAV & 1.00 & $0.88^{* *}$ & $0.88^{* *}$ & $0.73^{* *}$ & $0.87^{* *}$ & $0.80^{* *}$ \\
PCQ & & 1.00 & $0.99^{* *}$ & $0.93^{* *}$ & $0.85^{* *}$ & $0.75^{* *}$ \\
PCF & & 1.00 & $0.92^{* *}$ & $0.87^{* *}$ & $0.76^{* *}$ \\
PQD & & & 1.00 & $0.63^{* *}$ & $0.58^{*}$ \\
PQT & & & & 1.00 & $0.75^{* *}$ \\
Gordura & & & & & 1.00 \\
\hline
\end{tabular}

$* \mathrm{P}<0,05 ; * * \mathrm{P}<0,01 ; \mathrm{n}^{\circ}$ de observações $=18$. PAV = Peso animal vivo; $\mathrm{PCQ}=$ Peso carcaça quente; $\mathrm{PCF}=\mathrm{Peso}$ carcaça fria; $\mathrm{PQD}$ = Peso do quarto dianteiro; $\mathrm{PQT}=$ Peso do quarto traseiro; \% Gordura.

Fonte: Elaboração dos autores.

\section{Conclusões}

Os animais com maior desempenho ponderal e abate precoce, engordados em sistemas de criação, com uso de tecnologias (Sistema Silvipatoril), apresentam carne de melhor qualidade, o que revela a importância do manejo ambiental na produtividade e sustentabilidade da atividade pecuária na Amazônia Oriental. Búfalos criados no Sistema Silvipatoril se destacam, por apresentarem maior percentual de quarto traseiro, indicativo de 
maior quantidade de carnes nobres, com melhores marmóreo, espessura de gordura de cobertura e textura objetiva, com luminosidade característica de produto de boa qualidade.

\section{Agradecimentos}

À FAPESPA(Fundação de Amparo à Pesquisa do Estado do Pará) e Embrapa Amazônia Oriental pela concessão, respectivamente, da bolsa de Doutorado e infraestrutura para realização da pesquisa.

\section{Referências}

ALVES, D. D.; MANCIO, A. B. Maciez da carne bovina - uma revisão. Revista da Faculdade de Zootecnia, Veterinária e Agronomia, Uruguaiana, v. 14, n. 1, p. 193216. 2007.

ANDRIGHETTO, C.; JORGE, A. M.; ROÇA, R. O.; RODRIGUES, E.; BIANCHINI, W.; FRANCISCO, C. L. Características fisico-químicas e sensoriais da carne de bubalinos Murrah abatidos em diferentes períodos de confinamento. Revista Brasileira de Zootecnia, Viçosa, v. 37, n. 12, p. 2179-2184, 2008.

BERNARDES, O. Bubalinocultura no Brasil: situação e importância econômica (Buffaloes breeding in Brasil: position and economic relevancy). Revista Brasileira de Reprodução Animal, Belo Horizonte, v. 31, n. 3, p. 293 298, 2007.

BRASIL. Ministério da Agricultura, Pecuária e Abastecimento. Decreto n.30.691, de 29 de maio 1952 e alterado pela ultima vez pelo Decreto n.2.244 de 4de junho de 1997. Regulamento da Inspeção Industrial e Sanitária de Produtos de Origem Animal (RIISPOA). Diário Oficial [da] República Federativa do Brasil, Brasília, 5 jun. 1997. Seção 1, p. 11555.

CASTRO, A. C.; LOURENÇO JÚNIOR, J. B.; SANTOS, N. F. A.; MONTEIRO, E. M. M.; AVIZ, M. A. B.; GARCIA, A. R. Sistema silvipastoril na Amazônia: ferramenta para elevar o desempenho produtivo de búfalos. Ciência Rural, Santa Maria, v. 38, n. 8, p. 2395 2402, 2008.

FELÍCIO, P. E.; PICCHI, V.; CORTE, O. O. Sistematização de avaliação final de bovinos e bubalinos. II. Composição de carcaça. Campinas: ITAL, Centro de Tecnologia da Carne, 1979. (Boletim técnico, 3).

JORGE, A. M.; ANDRIGHETTO, C.; MILLEN, D. D.; HOCH, A. I. V.; MENEGUCCI, P. F. N. B. F.;
VARGAS, A. D. F. Características quantitativas da carcaça de bubalinos de três grupos genéticos terminados em confinamento e abatidos em diferentes estádios de maturidade. Revista Brasileira de Zootecnia, Viçosa, v. 34, n. 6, p. 2376-2381, 2005.

JORGE, A. M.; MENEGUCCI, P. F. N. B. F.; ANDRIGHETTO, C.; CALIXTO, M. G.; RODRIGUES, E.; POLIZEL NETO, A.; MOURÃO, R. C.; ATHAYDE, N. B.; FRANCISCO, C. L. Características de carcaça de bubalinos murrah castrados abatidos com diferentes períodos de confinamento. Recife, PE, 2006. In: ZOOTEC, 2006, Recife. Anais... Recife: Associação dos Criadores de Zebu, 2006. p. 54-60.

LOURENÇO JÚNIOR, J. B.; GARCIA, A. R. Produção animal no bioma Amazônico: atualidades e perspectivas. Revista Brasileira de Zootecnia, Viçosa, v. 35, n. 1, p. 63-83, 2006.

MACEDO, M. P.; BIANCHINI SOBRINHO, E.; RESENDE, F. D. Características de carcaça de bubalinos da raça mediterrâneo terminados em diferentes regimes alimentares. Viçosa, MG, 2000. In: REUNIÃO ANUAL DA SOCIEDADE BRASILEIRA DE ZOOTECNIA, 37., 2000, Viçosa. Anais... Viçosa: SBZ, v. 1, n. 1, 2000. p. 1-3.

MISSIO, R. L.; BRONDANI, I. L.; ALVES FILHO, D. C.; RESTLE, J.; ARBOITTE, M. Z.; SEGABINAZZI, L. R. Características da carcaça e da carne de tourinhos terminados em confinamento, recebendo diferentes níveis de concentrado na dieta. Revista Brasileira de Zootecnia, Viçosa, v. 39, n. 7, p. 1610-1617, 2010.

MORAES JÚNIOR, R. J.; GARCIA, A. R.; SANTOS, N. F. A.; NAHÚM, B. S.; ARAÚJO, C. V. Conforto ambiental de bezerros bubalinos (Bubalus bubalis Linnaeus, 1758) em sistemas silvipastoris na Amazônia Oriental. Acta Amazônica, Manaus, v. 40, n. 4, p. 629640, 2010.

MÜLLER, L. Normas para avaliação de carcaças e concurso de carcaça de novilhos. 2. ed. Santa Maria: Universidade Federal de Santa Maria, 1987. 31 p.

PACHECO, P. S.; RESTlE, J.; SILVA, J. H. S.; BRONDANI, I. L.; PASCOAL, L. L.; ARBOITTE, M. Z.; FREITAS, A. K. Desempenho de novilhos jovens e superjovens de diferentes grupos genéticos terminados em confinamento. Revista Brasileira de Zootecnia, Viçosa, v. 34, n. 3, p. 963-975, 2005.

RAO, V. A.; THUlASI, G.; RUBAN, W. S.; THANGARAJU, P. Optimum age of slaughter of nondescript buffalo: carcass and yield characteristics. Thai Journal of Agricultural Science, Bangkok, v. 42, n. 3, p. 133-138, 2009. 
RESTLE, J.; VAZ, F. N.; ALVES FILHO, D. C.; PASCOAL, L. L.; OLIVEIRA, A. N.; FATURI, C.; ARBOITTE, M. Z. Efeito do grupo genético e da heterose na composição física e nas características qualitativas da carcaça e da carne de vacas de descarte terminadas em confinamento. Revista Brasileira de Zootecnia, Viçosa, v. 31, n. 3, p. 1378-1387, 2002. Suplemento.

RODRIGUES, V. C.; ANDRADE, I. F.; FREITAS, R. T.; BRESSAN, M. C.; TEIXEIRA, J. C. Rendimentos do abate e carcaça de bovinos e bubalinos castrados e inteiros. Revista Brasileira de Zootecnia, Viçosa, v. 32, n. 3, p. 663-671, 2003.

SILVA, M. E. T.; FLEMMING, J. S.; MARTINE, J. L.; WASZCZYNSKY, N.; SOCCOL, C. R.Características quantitativas e qualitativas de carcaças de búfalos (Bubalus bubalis L.) Alimentados com diferentes proporções de volumoso e concentrado em regime de confinamento no Brasil. Revista Acadêmica-Ciências
Agrárias e Ambiental, São José dos Pinhais, v. 4, n. 3, p. 102-105, 2006.

SPANGHERO, M.; GRACCO, L.; VALUSSO, R.; PIASENTIER, E. In vivo performance, slaughtering traits and meat quality of bovine (Italian Simmental) and buffalo (Italian Mediterranean) bulls. Livestock Production Science, Amsterdam, v. 91, n. 1-2, p. 129141, 2004.

VAZ, F. N.; RESTLE, J.; BRONDANI, I. L.; PACHECO, P. S. Estudo da carcaça e da carne de bubalinos Mediterrâneo terminados em confinamento com diferentes fontes de volumoso. Revista Brasileira de Zootecnia, Viçosa, v. 32, n. 2, p. 393-404, 2003.

WHEELER, T. L.; KOOHMARAIE, M.; SHACKELFORD, S. D. Standardized Warner-Bratzler shear force procedures for meat tenderness measurement. Clay Center: Roman L. Hruska U. S. MARC. USDA, $1995.7 \mathrm{p}$. 